\title{
A Learn on Air Quality Monitoring in Tirunelveli
}

\author{
S.Rajesh, S.Vanitha, R.Premkumar
}

\begin{abstract}
Progressing air quality observing study in the Tirunelveli has given almost persistent information to the centralizations of gas-stage Pollutants from its inception in June 2013 to September 2014. In addition to PM10 focuses, Concentrations of organic carbons and total suspended particulate were likewise estimated. The rate of emission and concentration of the ambient air is controlled by the accompanying techniques. Altered West \& Gaeke's strategy for assurance of SO2 at the surrounding atmosphere Adjusted Jacob \& Hochheiser's strategy for assurance of NOx in encompassing atmosphere, and Gravimetric Method for the estimation of PM10. The surrounding checking and source portrayal information, results show that ATG tires and Cement plant outflows represented the majority of fine molecule mass focuses watched. At the Peak 24-h average concentrations of cement plant in $(2013-14.83 \mu \mathrm{g} / \mathrm{m3of} \mathrm{NO2}, 10.33 \mu \mathrm{g} / \mathrm{m3}$ of SO2 and

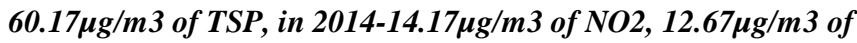

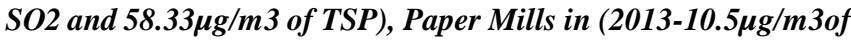
$\mathrm{NO2}, 8.67 \mu \mathrm{g} / \mathrm{m3}$ of $\mathrm{SO2}$ and $56.5 \mu \mathrm{g} / \mathrm{m3}$ of TSP, in $2014-9.97 \mu \mathrm{g} / \mathrm{m} 3$ of $\mathrm{NO} 2,9.27 \mu \mathrm{g} / \mathrm{m} 3$ of $\mathrm{SO} 2$ and $33.83 \mu \mathrm{g} / \mathrm{m} 3$ of

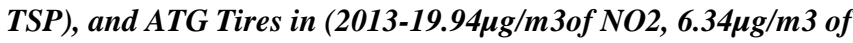

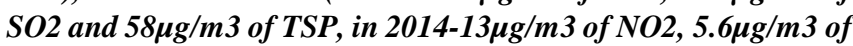
SO2 and $52.6 \mu \mathrm{g} / \mathrm{m3}$ of TSP). The results of gaseous and suspended solid pollutants concentration compare with the permissible concentration of $\mathrm{CPCB}$ Standards. That contamination scene was thought to have added to a considerable increment in mortality.
\end{abstract}

Keywords: Oxides of nitrogen, PM${ }_{10}$, Sulfur dioxide, TSP.

\section{INTRODUCTION}

The air we breathe in is a mix of gases, minimal solid \& liquid particle. A couple of substances start as of trademark sources whereas others be realized by man activities, for instance, our usage of motor vehicles, neighborhood activities, production, and commerce. Air pollution happens while the air contains substances in sums to could hurt the comfort or prosperity of individuals and animals or could mischief plants and materials. These mixes of atmosphere are called air toxins. Keeping the air quality adequate has turned into a significant assignment for chiefs just as for non-administrative associations. Particulate issue and vaporous outflows of contamination emanation from ventures and auto depletes are in charge of rising distress, expanding aviation route sicknesses and decay of masterful and social patrimony. (Sundaram haridoss et al., 2017)

Revised Manuscript Received on December 5, 2019

* Correspondence Author

S.Rajesh*, Department of Civil Engineering, Kalasalingam Academy Research \& Higher Education, Krishnankoil,, India. Email: srajesh@klu.ac.in,rajeshkvm88@gmail.com.

Dr.S.Vanitha, Department of Civil Engineering, Kalasalingam Academy Research \& Higher Education, Krishnankoil,, India. Email: svanitha@klu.ac.in

R.Premkumar, Department of Civil Engineering, Kalasalingam Academy Research \& Higher Education, Krishnankoil,, India. Email: rpremkumar@klu.ac.in

\section{A. Air Pollution in India}

In India, contamination has turned into an incredible theme of discussion at all dimensions and particularly the air contamination in view of the upgraded anthropogenic exercises, for example, copying petroleum products, gaseous petrol, coal \& oil toward control modern procedures and engine vehicles. From the hurtful synthetic intensifies, this consuming keen on the air, are $\mathrm{CO}_{2}, \mathrm{CO}, \mathrm{NO}_{\mathrm{x}}, \& \mathrm{SO}_{2}$.

i.Sulfur oxides: Eminent groupings of $\mathrm{SO}_{2}$ be shown with a smell of 'consuming matches' they related to men wellbeing impacts, particularly wising. Ecological impacts incorporate corrosive testimony and the arrangement of $\mathrm{PM}_{2.5}$. Plants, particularly lichens, are able to touchy near $\mathrm{SO}_{2}$ on moderately short focuses. The gas bothers aviation routes and eyes are famous to cause longer-term feeling ailments, additional cardiovascular infirmities, \& bronchitis. It likewise promptly causes smallness of inhalation and hacking among asthma sufferers. $\mathrm{SO}_{2}$ is likewise noteworthy supporter of the corrosive downpour, which harms the earth and annoys environments.

ii.Nitrogen Oxides: It causes extreme respiratory issues, particularly kids. At the point when joined to water, it frames nitric corrosive and further lethal nitrates. Nitrogen dioxide is likewise a primary part during the arrangement of $\mathrm{O}_{3}$ on the outside dimension. The gases disturb the lungs and have been identified to bring down the resistant framework. It might source fermentation and eutrophication unsafe to wellbeing, resources, social antiques, flora, and yields. Raised groupings of $\mathrm{NO}_{2}$ can likewise influence permeability through the making of a ruddy dark colored cloudiness. Notwithstanding, the impacts of NO taking place plant life is going underneath expanding examination in Europe, as $\mathrm{NO}_{2}$ is likewise a worry because of the job it acting like a forerunner toxin on behalf of $\mathrm{PM}_{2.5}$ arrangement and its relationship with the corrosive affidavit.

iii.Total suspended particulate: TSP is related to tasteful and natural effects, for example, the dirtying of resources or covering of plants. It can represent the best risk headed for human wellbeing in light of the fact that, for a similar mass, they assimilate more poisonous and cancer-causing mixes than bigger particles and enter all the more effectively profound into the lungs.

iv. $\mathbf{P M}_{10}$ : The increments during the particulate issue have been appeared near origin little, asymptomatic youngsters, in the two grown-ups and kids, especially wising. The progressions are regularly going with, particularly in grown-ups, by increments in manifestations, for example, incessant bronchitis or hack. (Anil Kumar Singhdeo and Nilamadhab Suna Gupta et al., 2010)

In South India, air contamination is far reaching inside town zones somewhere vehicles are significant donors and here a couple of different zones

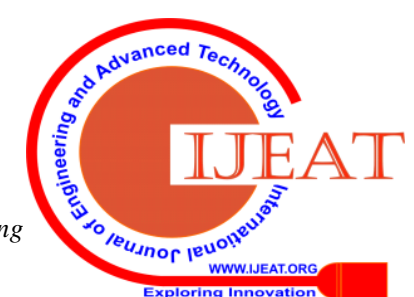




\section{A Learn on Air Quality Monitoring in Tirunelveli}

among a elevated convergence of ventures \& warm control plants. Vehicular outflows are specific worry because the ground-level sources and in this way cover the most extreme effect overall public.(Anon et al.,2005)

\section{B. Air Pollution Control in India}

The Act of pollution control in 1981 when corrected during 1987 expects to anticipate manage air contamination and safeguard quality of air. According to the TNPCB screens modern discharges during standard reviews of contamination air manage actions given through the enterprises. An AAQ review/heap discharge study is directed to survey the nature of the emanations let out.

\section{Air Quality Monitoring}

Quality air is observed through survey the convergence of atmospheric toxins emerging absent of discharges as of businesses just expanding vehicular inhabitants.

The current study has to assess the Air quality in Thamirabarani river basin around Tirunelveli, by using (i) Modified Gaeke \& West technique for sulphur dioxide (ii) Modified Hochheiser and Jacob technique for nitrogen oxides (iii) Cyclonic flow technique for the measurement $\mathrm{PM}_{10}$.

\section{STUDY AREA}

\section{A. Air quality monitoring sites}

The Study researches the convergence of the contaminations sulfur, nitro oxides, settle particle issue, and complete suspended settle particle produced as of different resources similar to autos, enterprises encompassing air nature of Tirunelveli. All things considered, Tirunelveli is a major city and it is beyond the area of imagination to expect to quantify the convergence of these real contaminations in all regions, so we have confined our investigation to three industries. There is India Cements (P) Ltd, Sun Paper mill, and ATG Tires. From these industries, every industry fixed six examining stations. The six stations were chosen considering the outflows contaminations from ground level and temperature. The examining station areas have appeared here table $1,2 \& 3$. The samples were gathered consistently for a long time. (2013\&2014).

Table-1: Air quality Sampling Station-1: India Cements Ltd

\begin{tabular}{|c|c|c|}
\hline $\begin{array}{l}\text { Sampling } \\
\text { Locations }\end{array}$ & Latitude & Longitude \\
\hline $\begin{array}{lr}\begin{array}{l}\text { A- Top } \\
\text { scaffolding } \\
\text { workshop }\end{array} & \text { of } \\
\end{array}$ & $8^{0} 47^{\prime} 20.699^{\prime \prime} \mathrm{N}$ & $77^{0} 43^{\prime} 47.25^{\prime \prime} \mathrm{E}$ \\
\hline $\begin{array}{ll}\text { B-On top } & \text { of } \\
\text { recreation club }\end{array}$ & $8^{0} 47^{\prime} 15.43{ }^{\prime \prime} \mathrm{N}$ & $77^{0} 43^{\prime} 24.67^{\prime \prime} \mathrm{E}$ \\
\hline $\begin{array}{l}\text { C- Top of Sankar Hr } \\
\text { sec school }\end{array}$ & $8^{0} 47^{\prime} 38.97^{\prime \prime} \mathrm{N}$ & $77^{0} 43^{\prime} 22.19^{\prime \prime} \mathrm{E}$ \\
\hline $\begin{array}{l}\text { D-Top of } \\
\text { scaffolding of north } \\
\text { security quarters }\end{array}$ & $8^{0} 47^{\prime} 28.93 ” \mathrm{~N}$ & $77^{0} 44^{\prime} 01.26^{\prime \prime} \mathrm{E}$ \\
\hline E- Boundary gate & $8^{0} 47^{\prime} 09.13^{\prime \prime} \mathrm{N}$ & $77^{0} 43^{\prime} 45.51^{\prime \prime} \mathrm{E}$ \\
\hline F-Top of near east & $8^{0} 47^{\prime} 11.96 ” \mathrm{~N}$ & $77^{0} 43^{\prime} 56.44^{\prime \prime} \mathrm{E}$ \\
\hline
\end{tabular}

boundary

Table-2: Air quality Sampling Station-2: Sun Paper Mills Ltd

\begin{tabular}{|c|c|c|}
\hline Sampling Locations & Latitude & Longitude \\
\hline $\begin{array}{l}\text { A-Top of scaffolding } \\
\text { near rice mill }\end{array}$ & $8^{0} 42^{\prime} 36.65^{\prime \prime} \mathrm{N}$ & $77^{0} 33^{\prime} 51.15^{\prime \prime} \mathrm{E}$ \\
\hline $\begin{array}{l}\text { B-On top of co-gen } \\
\text { plant security }\end{array}$ & $8^{0} 42^{\prime} 25.03^{\prime \prime N}$ & $77^{0} 33^{\prime} 21.53^{\prime \prime} \mathrm{E}$ \\
\hline $\begin{array}{l}\text { C-Top of scaffolding } \\
\text { near hollow block }\end{array}$ & $8^{0} 42^{\prime} 27.25 ” \mathrm{~N}$ & $77^{0} 33^{\prime} 17.94 ’ \mathrm{E}$ \\
\hline $\begin{array}{l}\text { D-Top of scaffolding } \\
\text { south side of co gen } \\
\text { plant, }\end{array}$ & $8^{0} 42^{\prime} 18.24 ” \mathrm{~N}$ & $77^{0} 33^{\prime} 15.85^{\prime \prime} \mathrm{E}$ \\
\hline $\begin{array}{l}\text { E-On building top of } \\
\text { super market }\end{array}$ & $8^{0} 42^{\prime} 24.70^{\prime \prime} \mathrm{N}$ & $77^{0} 34^{\prime} 03.48^{\prime \prime} \mathrm{E}$ \\
\hline $\begin{array}{l}\text { F-Top of scaffolding } \\
\text { near temple }\end{array}$ & $8^{0} 41^{\prime} 53.57^{\prime \prime} \mathrm{N}$ & $77^{0} 33^{\prime} 51.64$ 'E \\
\hline
\end{tabular}

Table-3: Air quality Sampling Station-3: ATG Tyres Ltd

\begin{tabular}{|c|c|c|}
\hline Sampling Locations & Latitude & Longitude \\
\hline $\begin{array}{l}\text { A-Top of scaffolding } \\
\text { near RO Plant }\end{array}$ & $8^{0} 500^{\prime} 37.69^{\prime \prime} \mathrm{N}$ & $77^{0} 44^{\prime} 21.76^{\prime \prime} \mathrm{E}$ \\
\hline $\begin{array}{l}\text { B-On top of } \\
\text { scaffolding near } \mathrm{SE} \\
\text { corner of boundary }\end{array}$ & $8^{0} 50^{\prime} 32.56^{\prime \prime} \mathrm{N}$ & 77044'20.99'"E \\
\hline $\begin{array}{l}\text { C-Top of Scaffolding } \\
\text { of EB sub station }\end{array}$ & $8^{0} 50^{\prime} 29.39^{\prime \prime} \mathrm{N}$ & $77^{0} 44^{\prime} 16.34^{\prime \prime} \mathrm{E}$ \\
\hline $\begin{array}{l}\text { D-Top of scaffolding } \\
\text { SW corner of } \\
\text { boundary, }\end{array}$ & $8^{0} 50^{\prime} 15.78^{\prime \prime} \mathrm{N}$ & $77^{0} 44^{\prime} 01.26^{\prime \prime} \mathrm{E}$ \\
\hline $\begin{array}{l}\begin{array}{l}\text { E-On top } \\
\text { scaffolding } \\
\text { rubber yard }\end{array} \\
\text { near }\end{array}$ & $8^{0} 50^{\prime} 18.43 ” \mathrm{~N}$ & $77^{0} 44^{\prime} 19.42^{\prime \prime} \mathrm{E}$ \\
\hline
\end{tabular}

- Station I, the India cements (P) Ltd., everything appeared to be fine about the setting up of the gadget and association for power aside from we must know about the specialists who thought that it was interested enough to contact and deal with it.

- Station II: In a local location, for example, the dispensary we found indistinguishable troubles from. Alongside that, there was likewise another issue that should have been dealt with. The secondary school that is before the plant was of a noteworthy concern while setting the gadget.

- $\quad$ Station III: In this majority packed measurement of the three points (picked) through the working day. Along these lines, now genuine safeguards were liked.

\section{EXPERIMENTAL ANALYSIS}

The techniques agreed intended for the gases Sulfur, Nitro oxidizes and $\mathrm{PM}_{10}$ are correspondingly.(i).Modified Geake-West Technique, (ii).Modified Jacob Hochheiser Technique, (iii).Gravimetric Technique 


\section{A. Modified Geake-West Technique}

The intention of this method is monitoring and examination of sulfur-dioxide in ambient air. The NAAQ standards on behalf of sulfur-dioxide, nitrogen-dioxide and $\mathrm{PM}_{10}$ are accessible in the chart table 4.

Table- 4:NAAQ standards

\begin{tabular}{|c|c|c|c|}
\hline Contaminant & $\begin{array}{c}\text { Time } \\
\text { biased } \\
\text { average }\end{array}$ & $\begin{array}{c}\text { Business, } \\
\text { Suburban, } \\
\text { Rustic and } \\
\text { other Areas }\end{array}$ & $\begin{array}{c}\text { Economically } \\
\text { Sensitive Area } \\
\text { (CPCB) }\end{array}$ \\
\hline \multirow[t]{2}{*}{$\begin{array}{l}\text { Sulfur Dioxide } \\
\left(\mathbf{S O}_{2}\right), \mu \mathrm{g} / \mathrm{m}^{3}\end{array}$} & $\underset{*}{\text { Annual }}$ & 50 & 20 \\
\hline & $\begin{array}{c}24 \mathrm{Hrs} \\
* *\end{array}$ & 80 & 80 \\
\hline \multirow{2}{*}{$\begin{array}{c}\text { Nitrogen } \\
\text { Dioxide } \\
\left(\mathrm{NO}_{2}\right), \mu \mathrm{g} / \mathrm{m}^{3}\end{array}$} & $\underset{*}{\text { Annual }}$ & 40 & 30 \\
\hline & $\begin{array}{c}24 \mathrm{Hrs} \\
* *\end{array}$ & 80 & 80 \\
\hline \multirow{2}{*}{$\begin{array}{c}\text { Particulate } \\
\text { Matter, } \mathrm{PM}_{10} \\
\mu \mathrm{g} / \mathrm{m}^{3}\end{array}$} & $\begin{array}{c}\text { Annual } \\
*\end{array}$ & 60 & 60 \\
\hline & $\begin{array}{c}24 \mathrm{Hrs} \\
* *\end{array}$ & 100 & 100 \\
\hline
\end{tabular}

*Annual Arithmetic methods for least 104 estimations in a year at a specific site taken two times every week 24 hourly at uniform interims.

**24 hourly or 8 hourly or 1 hourly checked qualities, as appropriate, will be conformed to $98 \%$ of the time in a year. $2 \%$ of the time, they may surpass the points of confinement yet not on two sequential long stretches of observing.

\section{i. Working procedure}

- $\quad$ Modified West-Gaeke technique

Sulfur-dioxide from air is caught up in an answer of potassium tetrachloro-mercurate. A dichlorosulphitomercurate complex, which opposes oxidation by the oxygen noticeable all around, is framed. When framed, this complex is steady to solid oxidants, for example, ozone and oxides of nitrogen and subsequently, the safeguard arrangement might be put away for quite a while proceeding examination. The complex is made to respond with para-rosaniline and formaldehyde to frame the strongly hued pararosaniline methyl sulphonic corrosive. The absorbance of the arrangement is estimated by methods for a reasonable spectrophotometer.

\section{ii. Sampling \& Analysis:}

Spot $30 \mathrm{ml}$ of retaining arrangement in an impinge and test for four hours at the stream rate of $1 \mathrm{~L} / \mathrm{min}$. In the wake of inspecting measure the volume of the test and move to an example stockpiling container Replace any water lost by dissipation during examining by adding refined water up to the alignment mark on the safeguard. Blend all together, pipette out $10 \mathrm{ml}$ of the gathered example into a $25 \mathrm{ml}$ volumetric flagon. Include $1 \mathrm{ml} 0.6 \%$ sulfamic corrosive and permit responding for 10 minutes to wreck the nitrite coming about because of oxides of nitrogen. Include $2 \mathrm{ml}$ of $0.2 \%$ formaldehyde arrangement and $2 \mathrm{ml}$ pararosaniline arrangement and makeup to $25 \mathrm{ml}$ with refined water. Set up a clear in a similar way utilizing $10 \mathrm{ml}$ of unexposed retaining reagent. After a $30 \mathrm{~min}$ shading improvement interim and before an hour, measure and record the absorbance of tests and reagent clear at $560 \mathrm{~nm}$. Use refined water; not the reagent clear, as the optical reference.

The real centralization of the sulfite arrangement is controlled by including abundance iodine and back titrating with standard sodium thiosulfate arrangement. To back-titrate, measure, by pipette, $50 \mathrm{ml}$ of the $0.01 \mathrm{~N}$ iodine arrangement into everyone of two $500 \mathrm{ml}$ iodine jars An and B. To flagon A (clear) include $25 \mathrm{ml}$ refined water and into carafe B (test) measure $25 \mathrm{ml}$ sulfite arrangement by pipette. Plug the flagons and permit to respond for 5 minutes. Set up the working sulfite-TCM arrangement in the meantime iodine arrangement is added to the carafes. By methods for a burette containing institutionalized $0.01 \mathrm{~N}$ thiosulfate, titrate every flagon thusly to a light yellow. At that point include a 5 $\mathrm{ml}$ starch arrangement and proceed with the titration until the blue shading disappears.

Plot a bend absorbance (Y pivot) versus focus (X hub). Draw a line of best fit and decide the slant. The corresponding of incline gives the adjustment factor $(\mathrm{CF})$.

Concentration of sulfite arrangement:

$\mathrm{C}=\left(\left(\mathrm{V}_{1}-\mathrm{V}_{2}\right) \times \mathrm{N} \times \mathrm{K}\right) / \mathrm{V}$

Where, $\mathrm{C}=\mathrm{SO}_{2}$ concentration in $\mathrm{mg} / \mathrm{ml}$

$\mathrm{V}_{1} \quad$ = Capacity of thiosulfate for blank, $\mathrm{ml}$

$\mathrm{V}_{2}$ = Capacity of thiosulfate for sample, $\mathrm{ml}$

$\mathrm{N}=$ Normality of thiosulfate

$\mathrm{K}=32000$ (Milliequivalent wt of $\mathrm{SO}_{2} / \mu \mathrm{g}$ )

$\mathrm{V}$ = Capacity of standard sulphite solution, $\mathrm{ml}$

$\mathrm{C}\left(\mathrm{SO}_{2} \mu \mathrm{g} / \mathrm{m}^{3}\right)=(\mathrm{As}-\mathrm{Ab}) \times \mathrm{CF} \times \mathrm{Vs} / \mathrm{Va} \times \mathrm{Vt}$

Where, $\mathrm{C}=$ Concentration of $\mathrm{SO}_{2}, \mu \mathrm{g} / \mathrm{m}^{3}$

As = Absorbance of sample

$\mathrm{Ab}=$ Absorbance of reagent blank

$\mathrm{CF}=$ Alignment factor

$\mathrm{Va}=$ Capacity of air sampled, $\mathrm{m} 3$

Vs = Capacity of sample, $\mathrm{ml}$

$\mathrm{Vt}$ = Capacity of aliquot taken for analysis, $\mathrm{ml}$

\section{B. .Modified Jacob Hochheiser technique}

The intention of this method is monitoring and examination of nitrogen-dioxide in ambient air.

\section{i. Working Procedure}

Modified Jacob-Hochheiser technique Surrounding nitrogen-dioxide $\left(\mathrm{NO}_{2}\right)$ is gathered by percolating air through an answer of sodium hydroxide and sodium arsenite. The centralization of nitrite particle $\left(\mathrm{NO}_{2}\right)$ delivered during examining is resolved calorimetrically by responding the nitrite particle with phosphoric corrosive, sulfanilamide, and $\mathrm{N}$-(1-naphthyl)- ethylenediamine di-hydrochloride (NEDA) and estimating the absorbance of the profoundly hued azo-color at $540 \mathrm{~nm}$.

\section{ii. Sampling \& Analysis:}

Spot $30 \mathrm{ml}$ of engrossing arrangement in an impinger and test for four hours at the stream rate of 0.2 to $1 \mathrm{~L} / \mathrm{min}$. In the wake of examining measure the volume of the test and move to an example stockpiling bottle. Supplant any water lost by dissipation during inspecting by adding refined water up to the alignment mark on the safeguard, blend completely. Pipette out $10 \mathrm{ml}$ of the gathered example into a $50 \mathrm{ml}$ volumetric jar. Pipette in $1 \mathrm{ml}$

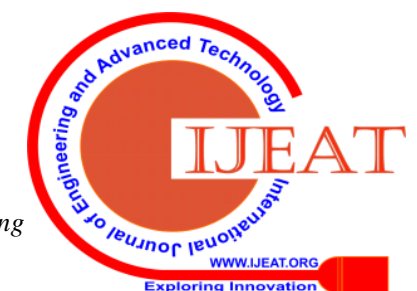




\section{A Learn on Air Quality Monitoring in Tirunelveli}

of hydrogen peroxide arrangement, $10 \mathrm{ml}$ of sulphanilamide arrangement, and $1.4 \mathrm{ml}$ of NEDA arrangement, with careful blending after the expansion of every reagent and makeup to $50 \mathrm{ml}$ with refined water. Set up a clear in a similar way utilizing $10 \mathrm{ml}$ of unexposed retaining reagent. After a 10 min shading advancement interim, measure and record the absorbance of tests and reagent clear at $540 \mathrm{~nm}$. Use refined water; not the reagent clear, as the optical reference Samples with an absorbance more prominent than 1.0 must be re-dissected in the wake of weakening an aliquot of the gathered examples with an equivalent amount of unexposed retaining reagent. An arbitrarily chosen $5-10 \%$ of the examples ought to be re-broke down as separated from an inward quality affirmation program.

Plot a bend absorbance (Y pivot) versus focus (X hub). Draw a line of best fit and decide the incline. The proportional of incline gives the alignment factor $(\mathrm{CF})$.

$\mathrm{C}\left(\mathrm{NO}_{2} \mu \mathrm{g} / \mathrm{m}^{3}\right)$

$$
=(\mathrm{As}-\mathrm{Ab}) \times \mathrm{CF} \times(\mathrm{Vs} / \mathrm{Va}) \times \mathrm{Vt} \mathrm{x} 0.83
$$

Where, $\mathrm{C}=$ Concentration of $\mathrm{NO}_{2}, \mu \mathrm{g} / \mathrm{m} 3$

As = Absorbance of sample

$\mathrm{Ab}=$ Absorbance of reagent blank

$\mathrm{CF}=$ Alignment factor

$\mathrm{Va}=$ Ccapacity of air sample, $\mathrm{m}^{3}$

Vs = Capacity of sample, $\mathrm{ml} \quad \mathrm{Vt}$ = Capacity of aliquot taken for analysis, $\mathrm{ml} 0.83=$ Sampling

effectiveness.

\section{Gravimetric technique}

The intention of this method is monitoring and examination of Particulate Matter $\mathrm{PM}_{10}$ in ambient air.

\section{i. Working Procedure}

Air is drawn through a size-specific gulf and through a $20.3 \times 25.4 \mathrm{~cm}(8 \times 10 \mathrm{in})$ channel at a stream rate, which is normally $1132 \mathrm{~L} / \mathrm{min}$. Particles with streamlined width not exactly the cut-purpose of the bay are gathered, by the channel. The mass of these particles is controlled by the distinction in channel loads preceding and in the wake of inspecting. The convergence of $\mathrm{PM}_{10}$ in the assigned size range is determined by partitioning the weight addition of the channel by the volume of air inspected.

\section{ii. Sampling \& Analysis:}

Field Sampling - Tilt back the gulf and secure it as indicated by the maker's guidelines. Release the faceplate wing nuts and expel the faceplate. Expel the channel from its coat and focus it on the help screen with the unpleasant side of the channel confronting upwards. Supplant the faceplate and fix the wing nuts to verify the elastic gasket against the channel edge. Tenderly lower the gulf. For consequently stream controlled units, record the assigned stream rate on the information sheet. Record the perusing of the passed time meter. The predetermined length of inspecting is normally 8 hours or 24 hours. During this period, a few perusing (hourly) of stream rate ought to be taken. After the required time of inspecting, record the stream meter perusing, take out the channel media from the sampler, and put in a holder or envelope.

Channel examination: Inspect the channel for stick openings utilizing a light table. Free particles ought to be evacuated with a delicate brush. Apply the channel recognizable proof number or a code to the channel on the off chance that it's anything but a numbered. Condition the channel in molding room kept up inside $20-30^{\circ} \mathrm{C}$ and 40 -half relative moistness or in a water/air proof desiccators for 24 hours. Take the beginning load of the channel paper (Wi) before testing. Condition the channel in the wake of inspecting in molding room kept up inside $20-30{ }^{\circ} \mathrm{C}$ and $40{ }^{\circ} \mathrm{C}$ half relative moistness or in a water/air proof desiccator for 24 hours. Take last weight of the channel paper (Wf)

Periodical adjustment of the sampler is being finished by Orifice Transfer Standard - The $\mathrm{PM}_{10}$ sampler alignment opening comprises a $3.175 \mathrm{~cm}$ (1.25 in) distance across the gap at last top of $7.62 \mathrm{~cm}$ (3 in) breadth by $20.3 \mathrm{~cm}$ ( 8 in) long-empty metal chamber. This opening is mounted firmly to the channel support instead of the bay during alignment. A little tap in favor of the chamber is given to gauge the weight drop over the opening. A stream rate of $1132 \mathrm{~L} / \mathrm{min}$ through the hole regularly brings about a weight contrast of a few creeps of water. The connection between weight distinction and stream rate is built up by means of an adjustment bend got from estimations against an essential standard, for example, a Roots meter at standard temperature and weight. Stream protections that reproduce channel protections are presented toward the finish of the calibrator inverse the hole by a lot of punctured round plates.

$\mathrm{PM}_{10} \mu \mathrm{g} / \mathrm{m}^{3}=(\mathrm{Wf}-\mathrm{Wi}) \times 106 / \mathrm{V}$

Where, $\mathrm{PM}_{10}=$ Concentration of Particulate

matter size below $10 \mathrm{~nm}, \mu \mathrm{g} / \mathrm{m} 3$

$\mathrm{Wf}=$ Initial weight of filter in $\mathrm{g}$

$\mathrm{Wi} \quad=$ Initial weight of filter in $\mathrm{g}$

$106=$ Aadaptation of $\mathrm{g}$ to $\mu \mathrm{g}$

$\mathrm{V}=$ Capacity of air sample, $\mathrm{m}^{3}$

\section{RESULTS AND DISCUSSIONS}

\section{A. Comparison of Air quality monitoring @ Station-1- from $2013 \& 2014$.}

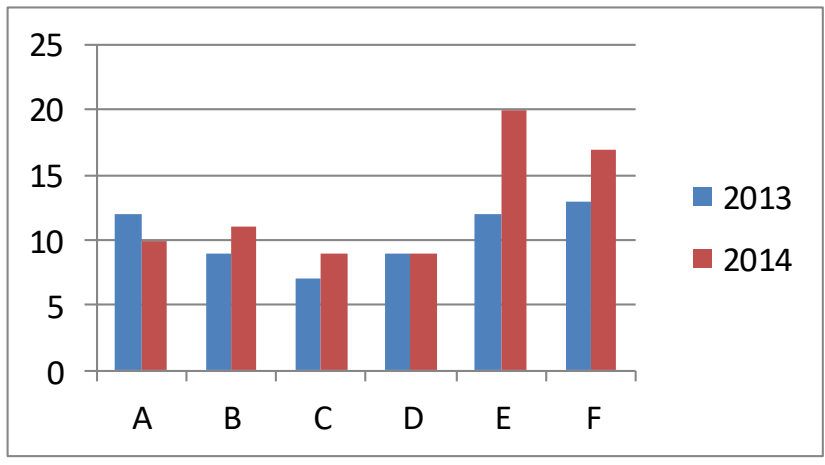

Fig.4.1.1. $\mathrm{SO}_{2}$ Emission variations

In $\mathrm{X}$ - Observation stations

$\mathrm{Y}$ - axis concentration in $\mu \mathrm{g} / \mathrm{m}^{3}$ 
B. Comparison of Air quality monitoring @ Station-2from $2013 \& 2014$.

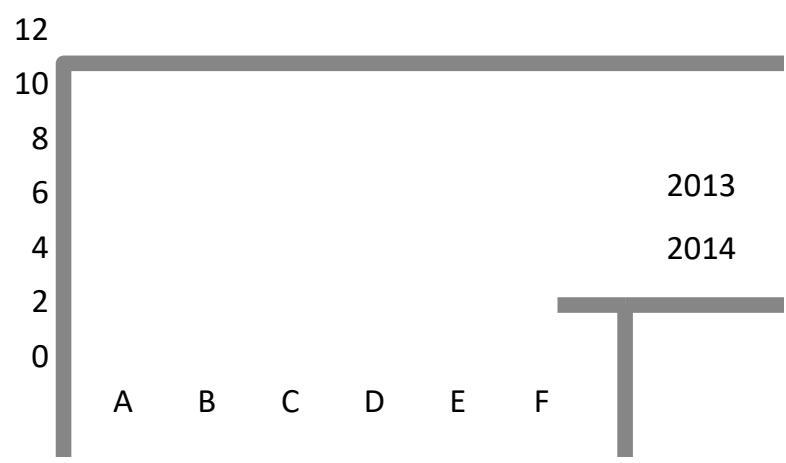

Fig.4.2.1. $\mathrm{SO}_{2}$ Emission variations

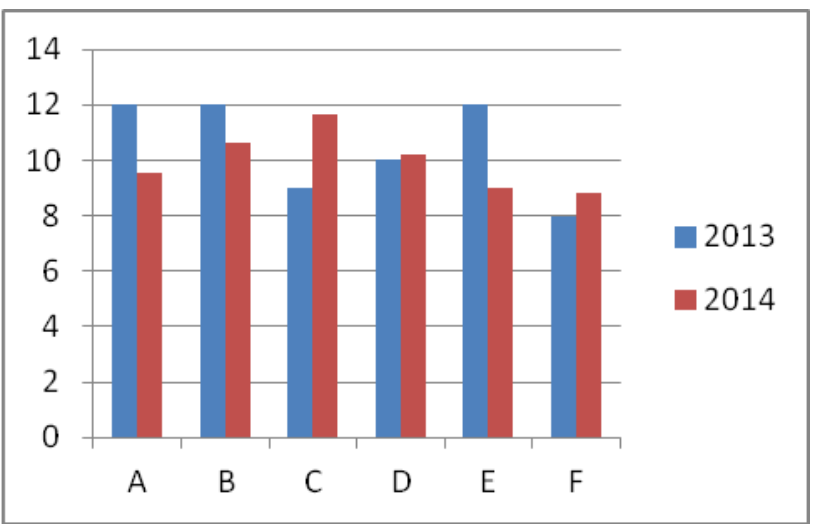

Fig.4.2.2. $\mathrm{NO}_{2}$ Emission variations

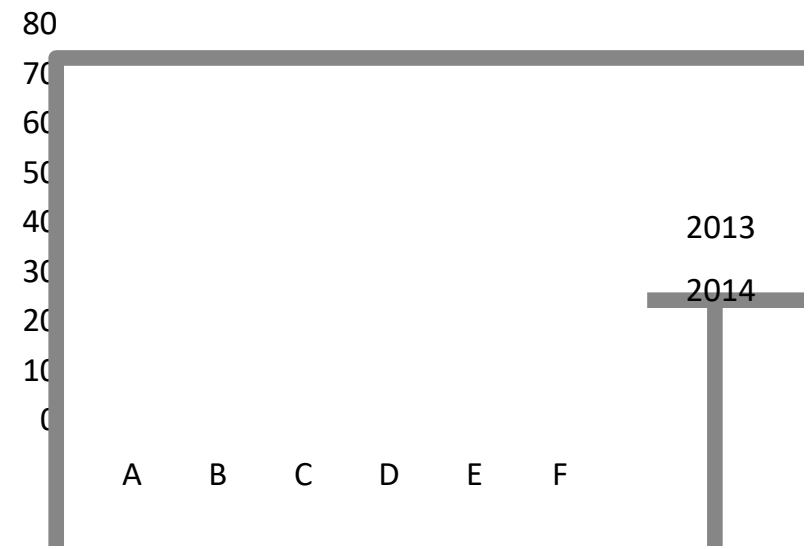

In $\mathrm{X}$-axis station points

$\mathrm{Y}$ - axis concentration in $\mu \mathrm{g} / \mathrm{m}^{3}$

C. Comparison of Air quality monitoring @ Station-3from $2013 \& 2014$.

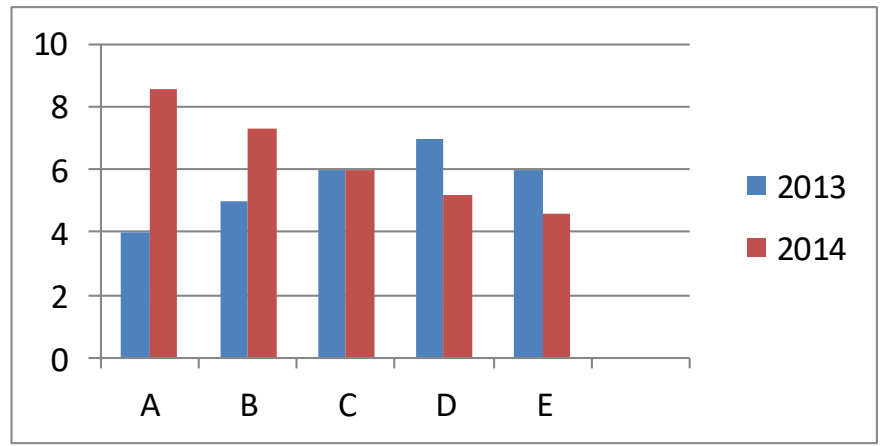

In $\quad \mathrm{X}$-axis station points

$\mathrm{Y}$ - axis concentration in $\mu \mathrm{g} / \mathrm{m}^{3}$

Progressing air quality observing study in the Tirunelveli has given almost persistent information to the centralizations of gas-stage In the study of air quality monitoring, it was observed that the Tirunelveli city and around area pollutants concentration level variation is there. The monitoring station pollutant concentration level is measured using the following methods

1.Altered West \& Gaeke strategy for $\mathrm{SO}_{2}$

2 Adjusted Jacob \& Hochheiser for NOx

3. Gravimetric Method for the estimation of PM10

From the Concentration of pollutants in the above three stations monitor from January 2013 to December 2014. The mean value of each pollutant $\left(\mathrm{SO}_{2}, \mathrm{NO}_{2} \& \mathrm{PM}_{10}\right)$ concentration level was calculated in table 5, $6 \& 7$. Table 4 is the allowable concentration level. To compare the allowable limit, the concentration level of pollutants is limited. In Station 1, the cement plant surrounded area, $\mathrm{PM}_{10}$ pollutant concentration level is increasing. In Station 2, Sun paper mill surrounded area compare to $\mathrm{PM}_{10}$, sulfur oxide, and nitrogen oxides concentration level allowable limit due to diluted in air. In Station 3, ATG Tyres (inside the city), pollutant level of nitrogen concentration is continuously increasing, and also $\mathrm{SO}_{2}$ and $\mathrm{PM}_{10}$ concentration increase within limit. Because the station 3, has more no vehicular emissions is there.

From the result and discussions section $4.1,4.2 \& 4.3$ are representing the pollutants $\left(\mathrm{SO}_{2}, \mathrm{NO}_{\mathrm{x}}\right.$, and $\left.\mathrm{PM}_{10}\right)$ level comparison.

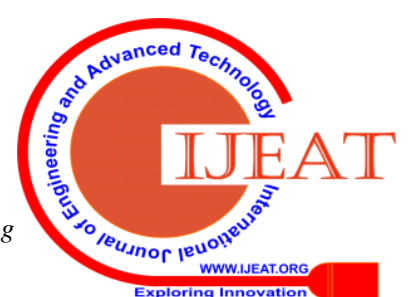




\section{A Learn on Air Quality Monitoring in Tirunelveli}

\section{IV.CONCLUSION}

In the study of air quality was evaluated utilizing three observing stations in Tirunelveli city along the Thamirabarani river, the investigations have uncovered the degrees of air toxins for $\mathrm{SO}_{2}, \mathrm{NO}_{\mathrm{x}}$, and $\mathrm{PM}_{10}$. The estimations of every one of these contaminations are seen to live especially underneath NAAQMS. These experimental studies in the air quality at these locals are likely due to the expanded urbanization (industry and increasing population) of Tirunelveli. As it should be obvious every one of the readings has been expanded at a reliable level, we should have some control strategies to stop air contamination. So we should have more consideration regarding limiting air contamination. The air quality is giving the all-encompassing perspective on air contamination levels. So from the outcome, it is clear that for now, the encompassing air along Thamirabarani waterway and Tirunelveli, does not require any consideration from the policymakers with the exception of the neighborhood, however perhaps later on we have to define a few different behaviour to neutralize that expansion during air contamination by explicit locals, because we cannot identify when the developing urbanization \& the passage will expand the atmosphere contamination point in Tirunelveli city considerably other than the large amount extreme passable breaking points.

\section{REFERENCES}

1. Anil Kumar Singhdeo and Nilamadhab Suna 2010.Monitoring of Sulfur dioxide, Nitrogen Oxides, $\mathrm{Pm}_{10}$ And TSP present in the Ambient Air of NIT Rourkela, Thesis..

2. Anon, 2005. Economic Appraisal 2003-04 \& 2004-05, Evaluation and Applied Research Department, Govt. of Tamil Nadu.

3. CPCB. 2006 National air quality status 2004. National ambient air quality monitoring series: NAAQMS/27/2006-2007, 131 pp. Central Pollution Control Board, New Delhi

4. D.Devakumar, S.Sempleb, and D.Osrina 2014. Biomass fuel use and the exposure of children to particulate air pollution in southern Nepal. the Environment International Journal, Science direct Vol.66:PP 79-87.

5. Hayley Hunga, Matthew MacLeodb, and Ramon Guardansc 2013. Toward the next generation of air quality monitoring: Persistent organic pollutants. Atmospheric Environment International Journal, Science direct Vol.80:PP 591-598.

6. I. Rivas, M. Vianab, and T. Morenob 2014. Child exposure to indoor and outdoor air pollutants in schools in Barcelona, Spain. the Environment International Journal, Science direct Vol.69:PP 200-212.

7. Kenji Sakurai, Yuichi Miyake, and Takashi Amagai 2013. Reliable passive-sampling method for determining outdoor 1,3-butadiene concentrations in air,. Atmospheric Environment International Journal, Science direct Vol.80:PP 198-203.

8. Leigh A. Beamisha, Alvaro R, and Osornio-Vargasb 2011. Air pollution: An environmental factor contributing to intestinal disease. Journal of Crohn's and Colitis, Vol.5,No4:PP 279-286.

9. Lisy Daniel 2017. A Study on Air pollution with Special reference to Vehicular Pollution. An Article. https://www.slideshare.net/KeerthanKAnish/article-72691259.

10. M. de las Obras-Loscertales, A. Rufas, and L.F. de Diego 2013. Effects of temperature and flue gas recycle on the $\mathrm{SO}_{2}$ and $\mathrm{NO}_{\mathrm{x}}$ emissions in an oxy-fuel fluidized bed combustor. Energy Procedia International Journal, Science direct Vol.37:PP 1275-1282.

11.Rosario Lanzafamea, Pier Francesco Scanduraa, and Fabio Famosoa 2014. Air quality data for Catania: analysis and investigation case study 2010-2011. Energy Procedia International Journal, Science direct Vol.45:PP 681-690.

12.S.Rajesh and Premkumar R , and Jeyadevi Neethipathi 2019, Relative Effectiveness of Methane (Biogas) Production from Dry Grass Soaked with Vegetable Waste, Poultry Waste and Cow Dung, Oriental Journal of Chemistry, Volume 35,Issue 2,April 2019,PP 732-737.

13.S.Sowmiya Lakshmi,S.Rajesh and Premkumar R ,2018, Removal of Organic Pollutants From Textile Dye Wastewater By Advanced Oxidation Process, International Journal of Civil Engineering \& Technology, (IJCIET), Volume 9,Issue 4,April 2018,:PP 452 - 461.
14.Sundaram haridoss, 2017.Study on air quality management in adyar river basin: A review, Journal of Industrial Pollution Control 33(1):PP 730-740. 15.Tom Harner, Ky Sua, Susie Genualdia, and Jessica Karpowicza 2013. Short communication Calibration and application of PUF disk passive air samplers for tracking polycyclic aromatic compounds (PACs). Atmospheric Environment International Journal, Science direct Vol.75:PP 123-128.

\section{AUTHORS PROFILE}

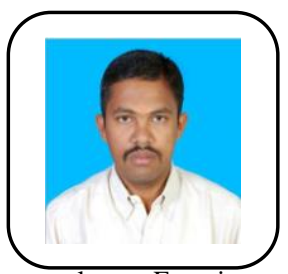

Er.S.Rajesh, Completed B.E(Civil) degree from GCE, Tirunelveli in 2009 and M.E(Environmental) degree from ACCET,Karakudi in 2013. He is working as Asst professor in KARE , Krishnankoil and Research scholar in KARE.His research area is Envionmental Engineerring..He is having 7 years Academic Experience and 10 years Industry consultancy Experience. He is Chartered Engineer \& Valuer in India. He is Professional member of the IOV, IEI and PE. He has published more than 10 SCOPUS indexed Journal and Conference in and around India.

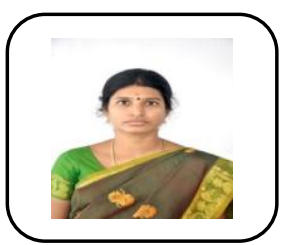

Dr.S.Vanitha, Completed B.E(Civil) degree from GCE, Triunelveli,M.E(Environmental) degree from AKCE, Krishnankoil and $\mathrm{PhD}$ from KARE, Krishanankoil. She is working as Associate professor in KARE. Her Research Area is Environmental Engineering. She has published SCOPUS indexed Journal. more than 15 no's of Indian and International

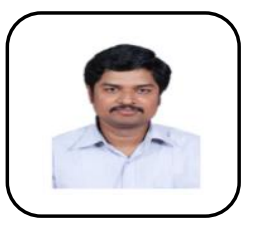

Er. R.Premkumar, had completed B.E degree in Civil Engineering and M.E degree in Structural Engineering from Anna University, Chennai, Tamil Nadu in 2008 and 2012 respectively. He is currently working as Assistant Professor in the department of Civil Engineering at Kalasalingam Academy of Research and Education. He has 2 year of industrial experience and 7 years experience in academics and consultancy. His current research interests are Geopolymer Concrete and Earthquake resistance structures. 


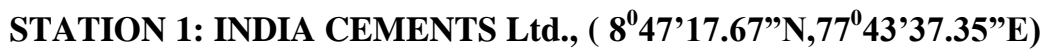

Observation year :2013

Temperature : 25 to 34 degree celsius

Weather

Humidity

Wind Speed

Direction

Category
: Clear Sky

: 56 to $76 \%$

: $6.2 \mathrm{~km} / \mathrm{hr}$

: NW-SE

: Red Large
Observation year :2014

Temperature : 27 to 36 degree Celsius

Weather : Clear Sky

Humidity : 56 to $72 \%$

Wind Speed $: 6.4 \mathrm{~km} / \mathrm{hr}$

Direction : NW-SE

Category : Red Large

Table 5.Ambient Air Quality (2013\&2014)

\begin{tabular}{|c|c|c|c|c|c|c|c|c|c|c|}
\hline \multirow{2}{*}{$\begin{array}{c}\text { S.N } \\
\text { o }\end{array}$} & \multirow[t]{2}{*}{ Location } & \multirow{2}{*}{$\begin{array}{c}\text { Direc } \\
\text { tion }\end{array}$} & \multirow{2}{*}{$\begin{array}{c}\text { Dista } \\
\text { nce }\end{array}$} & \multirow{2}{*}{$\begin{array}{l}\text { Ht } \\
\text { GL }\end{array}$} & \multicolumn{2}{|c|}{$\mathbf{P M}_{10} \mu \mathrm{g} / \mathrm{m}^{3}$} & \multicolumn{2}{|c|}{$\mathbf{S O}_{2} \mu \mathrm{g} / \mathrm{m}^{3}$} & \multicolumn{2}{|c|}{$\mathbf{N O}_{2} \mu \mathrm{g} / \mathrm{m}^{3}$} \\
\hline & & & & & 2013 & 2014 & 2013 & 2014 & 2013 & 2014 \\
\hline 1 & $\mathrm{~A}\left(8^{0} 47^{\prime} 20.69^{\prime \prime} \mathrm{N}, 77^{0} 43^{\prime} 47.25^{\prime \prime} \mathrm{E}\right)$ & NNE & 360 & 2 & 68.0 & 78.0 & 12.0 & 10.0 & 16.0 & 15.0 \\
\hline 2 & $\mathrm{~B}\left(8^{0} 47^{\prime} 15.43^{\prime \prime} \mathrm{N}, 77^{0} 43^{\prime} 24.67^{\prime \prime} \mathrm{E}\right)$ & SW & 500 & 3 & 44.0 & 39.0 & 9.0 & 11.0 & 16.0 & 14.0 \\
\hline 3 & $\mathrm{C}\left(8^{0} 47^{\prime} 38.97^{\prime \prime} \mathrm{N}, 77^{0} 43^{\prime} 22.19^{\prime \prime} \mathrm{E}\right)$ & NW & 650 & 5 & 34.0 & 33.0 & 7.0 & 9.0 & 10.0 & 10.0 \\
\hline 4 & $\mathrm{D}\left(8^{0} 47^{\prime} 28.933^{\prime} \mathrm{N}, 77^{0} 44^{\prime} 01.26^{\prime} \mathrm{E}\right)$ & $\mathrm{N}$ & 800 & 3 & 47.0 & 50.0 & 9.0 & 9.0 & 12.0 & 9.0 \\
\hline 5 & $\mathrm{E}\left(8^{0} 47^{\prime} 09.13^{\prime \prime} \mathrm{N}, 77^{0} 43^{\prime} 45.51^{\prime \prime} \mathrm{E}\right)$ & $\mathrm{S}$ & 350 & 2 & 82.0 & 68.0 & 12.0 & 20.0 & 17.0 & 16.0 \\
\hline 6 & $\mathrm{~F}\left(8^{0} 47^{\prime} 11.96^{\prime \prime} \mathrm{N}, 77^{0} 43^{\prime} 56.44^{\prime \prime} \mathrm{E}\right)$ & $\mathrm{E}$ & 600 & 3 & 86.0 & 82.0 & 13.0 & 17.0 & 18.0 & 21.0 \\
\hline
\end{tabular}

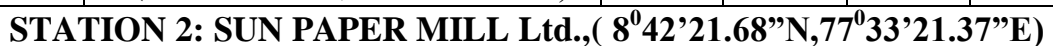

Observation year :2013

Temperature : 28 to 34 degree Celsius

Weather : Clear Sky

Humidity : 47 to $78 \%$

Wind Speed $: 3.2 \mathrm{~km} / \mathrm{hr}$

Direction : NE-SW

Category : Red Large
Observation year :2014

Temperature : 29 to 34 degree Celsius

Weather : Clear Sky

Humidity : : 467 to $78 \%$

Wind Speed $: 3.5 \mathrm{~km} / \mathrm{hr}$

Direction : NE-SW

Category : Red Large

Table 6.Ambient Air Quality (2013\&2014)

\begin{tabular}{|c|c|c|c|c|c|c|c|c|c|c|}
\hline \multirow{2}{*}{$\begin{array}{c}\text { S.N } \\
\text { o }\end{array}$} & \multirow[t]{2}{*}{ Location } & \multirow{2}{*}{$\begin{array}{c}\text { Direc } \\
\text { tion }\end{array}$} & \multirow{2}{*}{$\begin{array}{c}\text { Dista } \\
\text { nce }\end{array}$} & \multirow{2}{*}{$\begin{array}{l}\text { Ht } \\
\text { GL }\end{array}$} & \multicolumn{2}{|c|}{$\mathbf{P M}_{10} \mu \mathrm{g} / \mathrm{m}^{3}$} & \multicolumn{2}{|c|}{$\mathbf{S O}_{2} \mu \mathrm{g} / \mathrm{m}^{3}$} & \multicolumn{2}{|c|}{$\mathbf{N O}_{2} \mu \mathrm{g} / \mathrm{m}^{3}$} \\
\hline & & & & & 2013 & 2014 & 2013 & 2014 & 2013 & 2014 \\
\hline 1 & $\mathrm{~A}\left(8^{0} 42^{\prime} 36.65^{\prime \prime} \mathrm{N}, 77^{0} 33^{\prime} 51.15^{\prime \prime} \mathrm{E}\right)$ & NNE & 1000 & 3 & 76 & 17 & 10 & 9.10 & 12 & 9.55 \\
\hline 2 & $\mathrm{~B}\left(8^{0} 42^{\prime} 25.03^{\prime}{ }^{\prime}, 77^{0} 33^{\prime} 21.53^{\prime \prime} \mathrm{E}\right)$ & $\mathrm{N}$ & 100 & 3 & 62 & 28 & 9 & 9.43 & 12 & 10.60 \\
\hline 3 & $\mathrm{C}\left(8^{0} 42^{\prime} 27.25^{\prime}{ }^{\prime} \mathrm{N}, 77^{0} 33^{\prime} 17.94^{\prime \prime} \mathrm{E}\right)$ & NW & 200 & 3 & 56 & 50 & 7 & 10.08 & 9 & 11.66 \\
\hline 4 & $\mathrm{D}\left(8^{0} 42^{\prime} 18.24^{\prime \prime} \mathrm{N}, 77^{0} 33^{\prime} 15.85^{\prime \prime} \mathrm{E}\right)$ & $S$ & 200 & 3 & 39 & 45 & 9 & 9.74 & 10 & 10.20 \\
\hline 5 & $\mathrm{E}\left(8^{0} 42^{\prime} 24.70^{\prime \prime} \mathrm{N}, 77^{0} 34^{\prime} 03.48^{\prime \prime} \mathrm{E}\right)$ & $\mathrm{E}$ & 1200 & 4 & 52 & 34 & 10 & 8.79 & 12 & 8.99 \\
\hline 6 & $\mathrm{~F}\left(8^{0} 41^{\prime} 53.57^{\prime \prime} \mathrm{N}, 77^{0} 33^{\prime} 51.64^{\prime \prime} \mathrm{E}\right)$ & SSE & 800 & 3 & 54 & 29 & 7 & 8.45 & 8 & 8.83 \\
\hline
\end{tabular}

\section{STATION 3: ATG Tyres, ( 8050'35.26”N,77044'14.82”E)}

Observation year :2013

Temperature : 28 to 35 degree Celsius

Weather : Clear Sky

Humidity : 52 to $84 \%$

Wind Speed $: 3.3 \mathrm{~km} / \mathrm{hr}$

Direction : NW-SE

Category : Red Large, Rubber
Observation year :2014

Temperature : 28 to 37 degree Celsius

Weather : Clear Sky

Humidity : 48 to $80 \%$

Wind Speed $\quad: 3.0 \mathrm{~km} / \mathrm{hr}$

Direction : NW-SE

Category : Red Large,Rubber

Table 7.Ambient Air Quality (2013\&2014)

\begin{tabular}{|c|c|c|c|c|c|c|c|c|c|c|}
\hline S.N & Location & Direc & Dista & Ht & \multicolumn{2}{|c|}{$\mathbf{P M}_{\mathbf{1 0}} \boldsymbol{\mu \mathrm { g }} / \mathrm{m}^{3}$} & \multicolumn{2}{|c|}{$\mathbf{S O}_{2} \boldsymbol{\mu g} / \mathrm{m}^{3}$} & \multicolumn{2}{|c|}{$\mathbf{N O}_{2} \boldsymbol{\mu g} / \mathrm{m}^{3}$} \\
\hline
\end{tabular}

